\title{
Percepção de grupo de produtores familiares sobre a rastreabilidade na cadeia produtiva de hortaliças da Região Alto Tietê
}

Perception of a group of family farmers on traceability in the production chain of vegetables in the Alto Tietê Region

Percepción de un grupo de productores familiares sobre la trazabilidad en la cadena productiva de hortalizas en la Región del Alto Tietê

\begin{abstract}
Resumo
A rastreabilidade assegura o registro das informações sobre o 'caminho' que o alimento percorreu desde a produção no campo até a mesa do consumidor. A Anvisa conjuntamente com o Mapa, por meio da INC $\mathrm{n}^{\circ} 2$, de 2018 e INC $\mathrm{n}^{\circ}$ 1, de 2019, exigiu a adequação dos produtores para os procedimentos da rastreabilidade de produtos vegetais, Entretanto, quando os alimentos são produzidos por agricultores familiares, considerando das comunidades com grau de escolaridade baixo, falta de infraestrutura e muitos sem acesso a internet, a rastreabilidade passa a ser um grande desafio. Este artigo verificou a adequação do agricultor familiar à rastreabilidade da cadeia produtiva de alimentos, por meio da aplicação de estudo de caso múltiplo. Foi realizada uma pesquisa com nove propriedades rurais de hortaliças localizadas na região do Alto Tietê, Brasil. Nos resultados foi evidenciado que apenas um produtor implementou o sistema de rastreabilidade, mas para controle de somente $1 \%$ do total da sua produção, que atende grandes redes de fastfood. A maioria dos produtores tem o ensino fundamental incompleto (55\%), trabalham praticamente sozinhos na produção e contam com auxílio de familiares. Os resultados ainda apontaram que os produtores não têm como realizar a rastreabilidade devido a falta de registro dos insumos utilizados na produção, o que inviabiliza a implementação mesmo se a comunidade tiver infraestrutura de TI. Dessa forma, considera que a rastreabilidade é importante para a cadeia de alimentos, mas mediante a falta de estrutura legal dos insumos adicionado a falta de assistência técnica tornam dificil a adequação à INC 01, de 2019 pelos produtores do Alto Tietê. Palavras-chave: Cinturão verde; Controle de produção; Qualidade do processo; Segurança alimentar.
\end{abstract}

\begin{abstract}
The traceability ensures the registration of information about the 'path' that the food traveled from field production to the consumer's table. The Anvisa, together with the Mapa, through INC No. 2, of 2018 and INC No. 1, of 2019, demanded the adaptation of producers to the procedures of traceability of vegetable products. However, when the food is produced by family farmers, considering in communities with low levels of education, lack of infrastructure and many without internet access, traceability becomes a major challenge. This article verified the adequacy of the family farmer to the traceability of the food production chain, through the application of a multiple case study. A survey was carried out with nine vegetable farms located in the Alto Tietê region, Brazil. The results showed that one producer implemented the traceability system, but to control only $1 \%$ of its total production, which serves large fastfood chains. Most producers have incomplete elementary education (55\%), work practically alone in production and rely on the help of family members. The results also showed that producers are unable to carry out traceability due to the lack of registration of the inputs used in production, which makes implementation unfeasible even if the community has IT infrastructure. In this way, it considers that traceability is important for the food chain, but due to the lack of a legal structure for the inputs, added to the lack of technical assistance make it difficult for producers in Alto Tietê to comply to INC 01 of 2019.
\end{abstract}

Keywords: Green belt; Production control; Process quality; Food safety. 


\begin{abstract}
Resumen
La trazabilidad asegura el registro de información sobre el "camino" que recorrió el alimento desde la producción em el campo hasta la mesa del consumidor. La Anvisa, junto con el Mapa, a través del INC ${ }^{\circ} 2$, de 2018 y el $\mathrm{INC} \mathrm{N}^{\circ} 1$, de 2019, exigieron la adecuación de los productores a los procedimientos de trazabilidad de los productos vegetales, sin embargo, cuando los alimentos son producidos por agricultores familiares, considerando en comunidades con bajo nivel de educación, falta de infraestructura y muchas sin acceso a Internet, la trazabilidad se convierte en un gran desafío. Este artículo verificó la adecuación del agricultor familiar a la trazabilidad de la cadena de producción alimentaria, mediante la aplicación de un estudio de caso múltiple. Se realizó una encuesta en nueve fincas de hortalizas ubicadas en la región de Alto Tietê, Brasil. Los resultados mostraron que solo un productor implementó el sistema de trazabilidad, pero para controlar solo el $1 \%$ de su producción total, que atiende a grandes cadenas de comida rápida. La mayoría de los productores tienen educación primaria incompleta $(55 \%)$, trabajan prácticamente solos en la producción y cuentan con la ayuda de sus familiares. Los resultados también mostraron que los productores no pueden realizar la trazabilidad debido a la falta de registro de los insumos utilizados en la producción, lo que hace inviable la implementación incluso si la comunidad cuenta con infraestructura de TI. De esta manera, se considera que la trazabilidad es importante para la cadena alimentaria, pero debido a la falta de una estructura legal para los insumos, sumado a la falta de asistencia técnica dificultan que los productores del Alto Tietê se adapten al INC 01 de 2019.
\end{abstract}

Palabras clave: Cinturón verde; Control de producción; Calidad del proceso; Seguridad alimenticia.

\title{
1. Introdução
}

A produção de alimentos está cada vez mais tecnificada, seja no campo ou na indústria. Entretanto, apesar da realidade da sociedade do século XXI, tecnológica e consciente das necessidades socioambientais, ainda se encontra em muitas propriedades rurais aplicação de ferramentas rudimentares, comunidades com grau de escolaridade baixa, sem saneamento básico adequado tampouco infraestrutura de internet (Silva \& Machado, 2019). Não é uma realidade distante dos grandes centros, o cinturão verde de São Paulo está em torno de $65 \mathrm{~km}$ da capital.

As exigências da Agência Nacional de Vigilância Sanitária [Anvisa] e do Ministério da Agricultura, Pecuária e Abastecimento [Mapa], para a aplicação dos procedimentos da rastreabilidade de produtos vegetais, por meio da Instrução Normativa Conjunta [INC] N $^{\circ}$ 2, de fevereiro de 2018, com o Anexo III alterado pela INC nº 1, de 15 de abril de 2019 (Anvisa \& Mapa, 2018, 2019), chamou atenção pelo impacto na cadeia produtiva de frutas, raízes, tubérculos e hortaliças folhosas e não folhosas, principalmente, devido a maioria da produção desses produtos serem oriundos da agricultura familiar. $\mathrm{O}$ conceito de rastreabilidade está relacionado ao registro das informações sobre o produto, entre outras palavras, trata-se do histórico de produção e operação de um produto até chegar à mesa do consumidor (Regattieri et al., 2007). Esse conceito não reflete em somente conhecer a 'origem' do produto, mas para saber como ele foi produzido, armazenado, transportado e o seu ciclo de vida.

A agricultura familiar é a principal produtora de alimentos que abastece às mesas dos brasileiros, conforme dados do Instituto Brasileiro de Geografia e Estatística [IBGE] (IBGE, 2018), correspondendo 77\% de todos os estabelecimentos agrícolas e gerando cerca de 107 bilhões de reais, equivalente a 23\% de toda produção agropecuária brasileira. Compreendida como a atividade rural desempenhada por familiares e que a gestão da propriedade e da produção é realizada pelos proprietários, sendo o capital pertencente à família e os membros que residem nas propriedades rurais (Paes \& Zappes, 2016).

Ainda segundo o IBGE (2019), cerca de 67\% do pessoal empregado na agropecuária pertencem a agricultura familiar, ou seja, em torno de 10,1 milhões de pessoas. Tratando da região do Alto Tietê, entre os 12 municípios, Mogi das Cruzes se destaca com maior número de estabelecimento agropecuários (1.379) e observando à escolaridade dos Produtores, tem-se que cerca de $3 \%$ nunca frequentaram a escola, $52 \%$ até o primeiro grau, $28 \%$ segundo grau e por último $17 \%$ têm curso superior ou acima (IBGE, 2017).

A produção brasileira de hortifruti enfrenta grandes desafios quando o assunto é o controle do uso de insumos e a manipulação pelos produtores. No Brasil, a produção de hortaliças é caracterizada pelo consumo intensivo de defensivos agrícolas e pelo não cumprimento das boas práticas, em que muitas vezes são encontrados limites superiores aos permitidos 
pela legislação nesses alimentos (Ferreira, 2018). Assim, para garantir a qualidade do alimento que chega à casa dos brasileiros, um sistema de controle dos defensivos usados na agricultura é necessário, atendendo as exigências do mercado consumidor e assegurando o consumo de produtos in natura livres de resíduos de produtos químicos, prezando pela saúde da população.

A incessante busca por alto índice de produtividade, ou até mesmo, receio de perda de produção tem levado agricultores pequenos, médios e grandes ao uso descontrolado de defensivos agrícolas. Muitas vezes sem o conhecimento prático de como manipular, a quantidade ideal a ser utilizada na plantação e o tempo de carência. Essa realidade torna-se um risco a própria saúde do agricultor como dos consumidores dos produtos. Pesquisas brasileiras realizadas pelo Instituto de Defesa do Consumidor [IDEC] apontam irregularidades em praticamente todos os grupos de alimentos (Porto et al., 2007).

A utilização de defensivos agrícolas sem controle tem provocado várias consequências não somente ao ser humano que o consome por meio dos produtos, mas também ao ambiente, solos e lenções freáticos contaminados e saturados de produtos. Para Anvisa (2020a) o Programa de Análise de Resíduos de Agrotóxicos em Alimentos [PARA] é definido como "uma ação do sistema nacional de vigilância sanitária, coordenado pela Anvisa em conjunto com os órgãos estaduais e municipais de vigilância sanitária e laboratórios estaduais de saúde pública”. Ainda segundo a Anvisa, o PARA contribui para a segurança alimentar, orientando as cadeias produtivas sobre as inconformidades existentes e incentivando a adoção das boas práticas agrícolas.

Os resultados do programa possibilitam mapear a utilização de agrotóxicos nos alimentos de origem vegetal e avaliar o grau de exposição aos resíduos de agrotóxicos presentes nos alimentos, contribuindo para a tomada de decisões sobre o processo de utilização e a adoção de medidas restritivas ao uso de agrotóxicos (Anvisa, 2020b). Na mesma linha de raciocínio a Anvisa (2019) diz que agravos à saúde podem ocorrer depois de um longo período de consumo de alimentos contendo pequenas concentrações de resíduos de agrotóxicos.

De acordo com Aung e Chang (2014), a rastreabilidade é considerada uma ferramenta para cumprir a legislação e os requisitos de segurança e qualidade alimentar, em que também é considerado um sistema eficaz de monitoramento da cadeia produtiva de alimentos e contribui para aumentar a confiança do consumidor. Neste contexto, pressupõe que a rastreabilidade tem valor de mercado inerente ao processo de comercialização, visto que aumenta a credibilidade do produtor, melhora a percepção dos consumidores em relação a qualidade dos produtos ofertados ao mercado e garante a segurança alimentar requerida pela legislação.

Nessa inquietação foram levantadas duas questões de pesquisa: Q1 - qual o impacto das condições socioeconômicas para adequação dos agricultores ao sistema de rastreabilidade da cadeia de alimentos? Q2 - qual a visão do agricultor familiar sobre a INC e as exigências para aplicação da rastreabilidade? No contexto da agricultura familiar brasileira e a falta de infraestrutura de tecnologia nas áreas rurais, além de outros fatores como a falta de inclusão digital e o grau de escolaridade dos agricultores, este artigo teve como objetivo verificar a adequação do agricultor familiar à rastreabilidade da cadeia produtiva de alimentos, por meio da aplicação de estudo de caso múltiplo.

\section{Metodologia}

\subsection{Caracterização da pesquisa}

Foi realizado um estudo de caso múltiplo considerando os agricultores familiares localizados na região do Alto Tietê. De acordo com o IBGE (2017), a região do Alto Tietê, formada por 12 munícipios, tem 3.294 estabelecimentos rurais. Dessa forma, foi realizado o estudo de caso múltiplo com 9 produtores que atuam na agricultura familiar da região, selecionados por conveniência do pesquisador. A pesquisa teve a participação do produtor com mais influência na formação do mercado de hortaliças do Alto Tietê. 
Considerando o objetivo da pesquisa qualitativa, o método de estudo de caso foi o mais adequado para compreender a real situação dos agricultores da região quanto a adequação dos procedimentos de rastreabilidade na cadeia de alimentos. Segundo Pereira et al. (2009), o estudo de caso é uma investigação baseada em várias fontes de evidências apoiadas em proposições teóricas pré-estabelecidas para o levantamento e análise de dados no intuito de compreender o contexto de vida real.

\subsection{Instrumento e procedimento de coleta de dados}

Para condução do estudo de caso múltiplo, utilizou-se de um questionário semiaberto e estruturados, para coleta de dados. O questionário e o procedimento de pesquisa foram submetidos ao Comitê de Ética em Pesquisa e obteve Parecer $\mathrm{N}^{\mathrm{o}}$ 4.570.174/2021 favorável aplicação. Para construção do questionário usou-se de adaptações de informações do IBGE Instituto Brasileiro de Geografia e Estatística e da Instrução Normativa Conjunta No 2, de fevereiro de 2018, com o Anexo III alterado pela INC $\mathrm{n}^{\circ}$ 1, de 15 de abril de 2019 (Anvisa \& Mapa, 2018, 2019). Para responder as questões de pesquisa foram investigadas as seguintes variáveis:

1) características socioeconômicas: gênero, idade, grau de escolaridade, renda familiar, número de membros da família, tempo de atuação, condição legal do produtor, condição do produtor em relação a terra;

2) instalação rural e a cultura de produção: utilização das terras, tipo de cultura, sistema de preparo do solo, adubação, utilização de defensivos agrícolas, assistência técnica, mão de obra empregada, número de pessoas empregadas no cultivo, emprego de máquinas e implementos agrícolas; e

3) rastreabilidade da cadeia produtiva de alimentos: conhecimento em informática, rede de internet, sistema de rastreabilidade, quanto tempo utiliza a rastreabilidade, conhecimento sobre a INC 01 , dificuldade de adequação do processo, implementação e aquisições necessárias para implantação do sistema de rastreabilidade, percepção quanto uso do sistema de rastreabilidade e o mercado (preço de venda, aumento de vendas, qualidade dos alimentos, credibilidade etc.), entre outros pontos de investigação.

A coleta de dados foi por meio de entrevistas realizada pelos pesquisadores, seguindo o questionário semiestruturado. Antes da aplicação do questionário, os produtores foram livres e esclarecidos sobre o objetivo, riscos e benefícios da pesquisa, entre outros pontos importantes constantes no Termo de Consentimento Livre e Esclarecido [TCLE].

\subsection{Análise de dados}

Para a caracterização do estudo, utilizou-se de estatística descritiva univariada, com o uso de tabelas de frequência e estudo de proporcionalidade. Entretanto, para responder a Q1, buscou-se verificar a existência de associação entre variáveis socioeconômicas e as condições de adequação dos agricultores à rastreabilidade, por meio da estatística descritiva bivariada, conforme recomendado por Fávero e Belfiore (2021), com o uso tabela de classificação cruzada (cross-tabulation) e o uso de estatística qui-quadrado $\left(\chi^{2}\right)$, Eq. 1.

$$
\chi^{2}=\sum_{i=1}^{l} \sum_{j=1}^{J} \frac{(O i j-E i j)^{2}}{E i j}
$$

Onde, $I=$ número de categorias da variável $\mathrm{X} ; J=$ número de categorias da variável $\mathrm{Y} ; O i j=$ quantidade de observações ( $i=$ categoria da variável $\mathrm{X} ; j=$ categoria da variável $\mathrm{Y}) ; E i j=$ frequência esperada de observações $(i=$ categoria da variável $\mathrm{X} ; j=$ categoria da variável $\mathrm{Y}$ )

Neste estudo, considerou-se um nível de confiança de $95 \%$ e p-valor = 0,5. Para responder a Q2, apresentou-se os relatos dos produtores de forma descritiva. 


\section{Resultados e Discussão}

Das nove propriedades rurais visitadas, cerca de $80 \%$ dos participantes são do sexo masculino e $20 \%$ do sexo feminino, sendo que $45 \%$ encontram-se na faixa etária de 36 a 45 anos e $55 \%$ acima de 46 anos. Assim como, a maioria apresenta escolaridade fundamental incompleto (55\%) e menos da metade tem o ensino médio completo (45\%). Analisando as variáveis de renda familiar e pessoas por família, nota-se que independente da renda, a maioria das propriedades participantes tem de 3 a 4 pessoas, Figura 1.

Figura 1: Distribuição de Renda por número de pessoas por família.

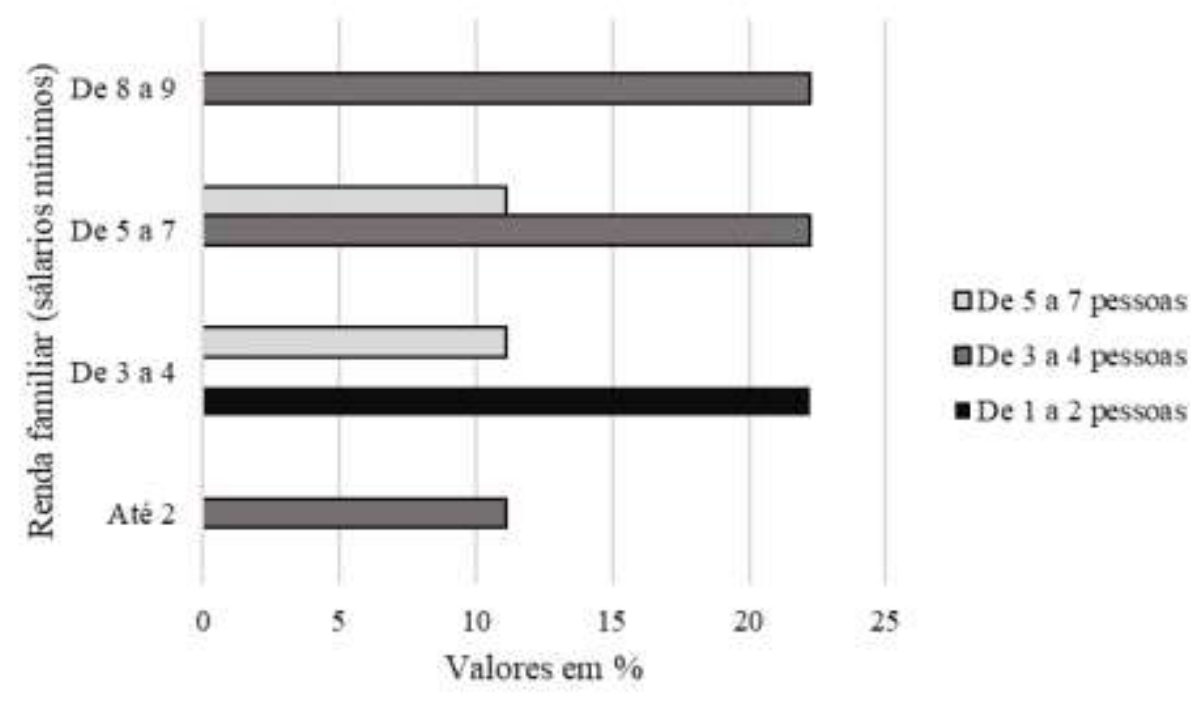

Fonte: Autores.

Para Savian (2014) a agricultura brasileira tem enfrentado um processo de despovoamento no qual se destaca a saída dos jovens e a ausência deles coloca em risco a sucessão geracional da agricultura familiar. O autor ainda trata da importância da renda para a sucessão geracional, visto que a insatisfação com a renda se torna um fator de desmotivação e contribui para a não permanência no campo (Savian, 2014). Fonseca et al. (2015) também contribuiu com a discussão destacando que uma das grandes causas do êxodo rural é devido a implantação de um modelo econômico moderno na produção agropecuária, com a adoção do novo modelo padrão tecnológico, baseado em insumos agrícolas e na mecanização; logo, os produtores de baixa renda não conseguem realizar mecanização em sua produção e têm baixo rendimento de produtividade sendo submetidos à desvantagem no mercado.

O processo de modernização é um elemento que influencia o êxodo rural na qual causa o envelhecimento da agricultura familiar sendo que os jovens se deslocam para os centros urbanos em busca de melhores oportunidades de emprego (Loper Aires \& Salamoni, 2012). Seguindo com a análise da associação entre escolaridade e renda, observou-se que os produtores com ensino fundamental incompleto se concentram entre 4 e 5 salários-mínimos e os produtores com ensino médio acima de 7 e 8 salários-mínimos $\left(\chi^{2}=6,3 ; p=0,09789\right)$. Segundo Hoffmann e Kageyama (2016), melhoria das condições de vida das famílias agrícolas, depende de uma elevação do nível de escolaridade para as quais a agricultura ajuda a compor a renda domiciliar, isso possivelmente contribuiria para melhor rentabilidade na produção.

De acordo com Savian (2014), as atividades ligadas à agropecuária encontram diversas dificuldades na produção como o acesso à tecnologia, custo dos insumos e na comercialização como inserção no mercado e preços baixos dos produtos agrícolas que influenciam na obtenção de renda. Sendo assim a baixa renda e escolaridade podem ser um agravante para o 
agricultor familiar se adequar a INC.

Observando a distribuição dos participantes por tempo de atividade agrícola e a renda familiar, percebe-se que a maioria apresentou renda familiar acima de 3 salários-mínimos, e acima de 21 anos de experiência na atividade agrícola $\left(\chi^{2}=\right.$ 13,5; $p<5 \%$ ). Isso reforça que as pessoas entrevistadas conhecem muito bem o seu negócio, e por terem esta experiência, conseguem melhorar sua renda com o tempo, assim como citou Marino (2006) o conhecimento é essencial quando se fala em vantagem competitiva e a tecnologia converte desafios em oportunidades. Ainda para a autora, não há vantagem competitiva sustentável senão através do que a empresa sabe, como ela consegue utilizar o seu conhecimento e quão rápido se aprende algo novo.

\subsection{Arranjo produtivo de hortaliças do Alto Tietê}

A amplitude de terra distribuída entre os produtores varia de 0,6 a 100,0 hectares. A classificação das propriedades rurais ocorre por módulos fiscais, sendo que das nove propriedades, oito se enquadram como pequenas propriedades (até quadro módulos fiscais), e uma classificada como grande propriedade (acima de 15 módulos fiscais) (Brasil, 1993; Infraestrutura e Meio Ambiente, 2014; Incra, 2020). Com relação a condição legal do agricultor a maioria se declarou produtor individual $(67 \%)$ e os demais como cooperados, e em relação a condição da terra há uma distribuição entre proprietários e arrendatários, arrendatários e assentados. No local do estudo existe as cooperativas que é descrito por Wiese et al. (2014), como associações criadas para prestar serviços econômicos para seus cooperados para que consigam desenvolver ações socioeconômicas direcionadas para seus integrantes cooperados, seus familiares e comunidade.

A comercialização dos produtos agrícolas ocorre de forma direta e indireta, sendo relatado que a maioria adota o sistema indireto, com a presença do atravessador, devido os produtores não terem condições para realizar a própria venda (Figura 2). O arranjo produtivo trabalha com dois tipos de comércio, conhecido como 'pé' ou 'baciada'. No que se refere a venda por pé ou unidade o comerciante que compra diretamente de produtores ou por atravessadores, adquire seu produto em caixas com várias unidades e ao vender a varejo, essa mercadoria é exposta em sua feira ou quitanda junto com mercadorias de outros fornecedores, pois raramente a compra do produto por atacado são de mesma origem, o que atrapalha o processo de rastreio da cadeia.

A outra forma comercializada é por baciada, sendo vendido produtos nas quais estão muito tempo a amostra, ou são de tamanhos e qualidade que não se sobressaem aos que são vendidos por unidade, assim, o comerciante reúne alguns produtos, seja em saquinhos plásticos ou em bacias (equivalente a promoção), o que leva novamente a uma mescla de alimentos já que o intuito do comerciante é vender o alimento evitando assim seu desperdício. Essas técnicas de vendas dificultam ainda mais a fiscalização para saber a origem e procedência do alimento.

Figura 2: Fluxo do arranjo produtivo de hortaliças do Alto Tietê

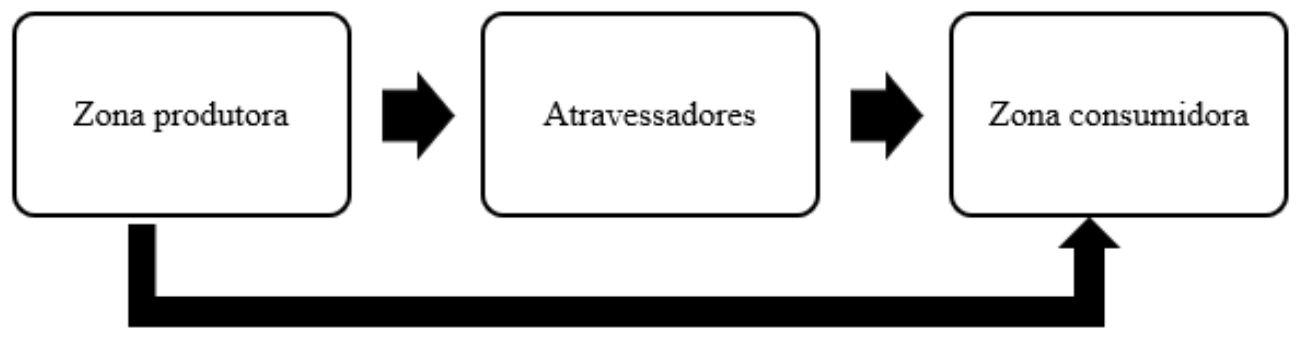

Fonte: Autores. 
A zona produtora refere-se a todos os agricultores que atuam na região com a produção de hortaliças para abastecer o mercado. Os atravessadores são empresas que atuam como intermediários, formando o elo entre os produtores e o mercado consumidor, que pode formado por feiras-livres, quitandas, atacados e mercados. Os atravessadores, em geral, são responsáveis pelo transporte dos produtos da zona produtora até a zona consumidora. Estes também são responsáveis pela mesclagem de alguns produtos como folhosas e a mistura de lotes, o que prejudica o sistema de rastreabilidade.

O cultivo nas propriedades envolve os diversos tipos de lavouras (cebola, salsa, coentro, repolho, batata, cenoura, alface, rabanete, acelga, couve, rúcula, escarola, mostarda etc.) e uma pequena área para pastagem. Como visto, uma dentre as propriedades rurais tem maior capacidade produtiva devido seu tamanho e organização, com a utilização de tratores, semeadeiras e adubadora, diferente das demais que faz uso apenas de tratores.

A maioria dos produtores participantes do trabalho atuam com cultivo convencional (89\%), com exceção de apenas um produtor que faz o plantio direto na palha. Todos utilizam algum tipo de adubação e de defensivos agrícolas (fungicida, inseticida herbicida). Verificou-se que não há associação entre o tempo de experiência do agricultor na atividade e o tipo de adubo aplicado na lavoura, Tabela 1. Resultado semelhante se observou entre o tempo de experiência do produtor e o tipo de defensivo agrícola aplicado $\left(\chi^{2}=6,73 ; p=0,3467\right)$.

Tabela 1: Distribuição do tempo de experiência como agricultor por tipo de adubação utilizada na lavoura, valores em \%

\begin{tabular}{cccc}
\hline & \multicolumn{3}{c}{ Tipo de adubação utilizada (\%) } \\
\hline $\begin{array}{c}\text { Tempo de experiência como } \\
\text { agricultor (anos) }\end{array}$ & Biológico & Orgânico & Químico \\
De 11 a 20 & 7,14 & - & 14,28 \\
De 21 a 30 & - & 7,14 & 7,14 \\
De 31 a 40 & - & 7,14 & 14,28 \\
Acima de 41 & - & 21,42 & 21,42 \\
\hline
\end{tabular}

$$
\chi^{2}=5,37 ; p=0,4977 \text {. Fonte: Autores. }
$$

A maioria dos produtores afirmou que recebe assistência técnica, contudo de fornecedores de produtos agrícola, e que raramente há assistência técnica por parte do governo ou organizações agrícolas. Os agricultores exemplificaram uma visita técnica pela entidade sem fins lucrativos atuante no apoio às micro e empresas e ressaltam quão mal preparados e não aptos estão para desempenhar seu papel junto as comunidades rurais, por meio de palestras com poucas informações técnicas voltadas para o seu tipo de cultivo e que agreguem ao seu tipo de comercialização. A constatação obtida neste estudo, corrobora com os esclarecimentos de Lourenzani et al. (2008 como citado em Carvalho, 2013, p. 21), sobre projetos que envolve a agricultura familiar com crédito e assistência técnica subsidiados, mas com baixo desempenho devido adoção de planejamento produtivo inconsistente.

Segundo Fonseca et al. (2015), entre as razões do êxodo rural se encontra a falta de apoios financeiros por parte das organizações governamentais para o pequeno agricultor, o que pode explicar parte das queixas dos entrevistados.

Entre as pequenas propriedades, observa-se que a maioria (67\%) não emprega mão de obra, sendo a atividade mantida pela própria família, apenas 33\% empregam mão de obra, com ou sem grau de parentesco variando entre 4 e 6 parceiros. Já a grande propriedade emprega mão de obra sem grau de parentesco (acima de 16 funcionários).

Importante ressaltar que algumas propriedades trabalham com o termo parceiros e não empregados, sendo que no sistema de parcerias, os trabalhadores recebem uma determinada metragem de terra do proprietário para cultivar e fazer a 
própria venda do que plantou, cultivou e colheu, em contrapartida auxilia na propriedade, e dependendo do acordo pode até ganhar uma comissão por hectare trabalhado. Para Gregolis et al. (2012), "parceiros são trabalhadores que, independentemente da posse da terra, trabalham em sistema de divisão de tarefas, custos e dividendos", diferente dos meeiros que são trabalhadores que não possuem terra e trabalham para proprietários em troca de uma parcela da produção; dessa forma, os custos são arcados pelo proprietário, cabendo ao meeiro o desenvolvimento das atividades de trabalho (Gregolis et al., 2012).

\subsection{Rastreabilidade na cadeia produtiva de hortaliças}

Os resultados dessa pesquisa mostram que todos os proprietários entrevistados têm acesso internet na propriedade, contudo $88 \%$ não tem conhecimento básico de informática. Da mesma forma, tem-se que apenas o produtor de grande porte que afirmou realizar rastreabilidade da sua produção. Pesquisa realizada por Carvalho (2013), revelou que apenas $24 \%$ dos agricultores informaram ter acesso a internet via rádio nas residências ou na Associação pertencente.

Durante as entrevistas, muitos produtores informaram que trabalham sozinhos no cultivo da lavoura, às vezes, tem auxílio de outro membro, o que implica na falta de tempo de dedicação às outras atividades, tais como: educação e lazer. Para 'ter bons resultados', o produtor precisa estar sempre atento para a irrigação diária, momento de colheita, preparar e adubar a terra, aplicar os defensivos contra insetos e pragas. De acordo com Loper Aires e Salamoni (2012), "as atividades agrícolas exigem tempo e energia dos agricultores, principalmente, se forem realizadas com práticas tradicionais".

Para famílias descapitalizadas não possuem condições para investir em modernizações e não detém de tempo para aperfeiçoamento de tecnologias necessárias para aumentar a produtividade da área. Ainda segundo Loper Aires e Salomoni (2012), com a concorrência de países desenvolvidos uma alternativa para os agricultores é a aquisição de novas tecnologias agrícolas, no entanto para as pequenas propriedades o para o investimento há um alto custo em que não há retorno financeiro e benefícios à sua aquisição.

Observa-se que a maioria dos agricultores tem interesse em estudar, aprender a utilizar computadores e outras ferramentas de auxílio no controle e organização da propriedade. Na região, há a Associação dos Produtores Rurais de Jundiapeba e Região [APROJUR], onde ocorre reuniões semanais tratando de assuntos como a própria adequação a rastreabilidade, inclusão digital para desenvolvimento de ferramentas de controle, planejamento estratégico para melhorar as condições dos produtores rurais além de pautas sobre a gestão do assentamento. Entretanto, o tema inclusão digital não é discussão recente, considerando as necessidades dos agricultores para o apoio à gestão da empresa e a tomada de decisão (Carvalho, 2013).

$\mathrm{Na}$ perspectiva da agricultura familiar em relação a rastreabilidade, o uso das ferramentas tecnológicas se torna essencial. Todos os participantes da pesquisa têm conhecimento sobre a Instrução Normativa Conjunta [INC] $\mathrm{N}^{\circ} 2$, de fevereiro de 2018, com o Anexo III alterado pela INC nº 1, de 15 de abril de 2019, e a obrigatoriedade de implementar a rastreabilidade, mas apenas a grande propriedade consegue realizar em até 1\% da produção, ou seja, $99 \%$ da produção não está contemplada no sistema de rastreabilidade (Anvisa \& Mapa, 2018, 2019).

Para Almeida et al. (2016), uma das barreiras para a agricultura familiar é a dificuldade na adoção de práticas de manejo recomendadas, visto que os costumes e a cultura acabam levando à resistência na adoção de novas tecnologias, ainda que estas sejam simples. Há poucos trabalhos práticos direcionados ao agricultor familiar quando se trata à tecnologia aplicada e às técnicas de controle e o monitoramento ao longo das cadeias produtivas, o que tem provocado uma série de empecilhos na implementação de sistemas de rastreabilidade (Silva, 2009). Considerando a realidade dos produtores e as condições de mercado, Silva (2009), ressaltou que a rastreabilidade pode se tornar uma barreira de entrada dos produtores no mercado, caso não consigam se adequar, devido ao custo da infraestrutura necessária à execução do monitoramento e ao treinamento do pessoal envolvido na atividade. Isto também pode contribuir para a formação de um mercado paralelo de alimentos não 
rastreáveis e sem controle de comercialização.

Quando questionados sobre o grau de dificuldade para atender a INC 01, considerando os critérios listados na Tabela 2, nota-se que a maioria tem condições de implementar a parte hardware do sistema, como infraestrutura em tecnologia da informação [TI] e informações pertinentes aos fornecedores e insumos, classificando esses critérios com menor grau de dificuldade; do mesmo modo, percebe-se maior grau de dificuldade para implementação da parte software, tais como treinamento de pessoal envolvido na produção, como, sistema de identificação e sistema de codificação de alimentos (etiquetagem de lotes de produção com seus respectivos dados) e a sistema de captura e registro de dados ( $Q R$ Code). Ainda observou que 50\% apresentam preocupações no capital investido, para implementação do sistema de rastreabilidade da cadeia.

Tabela 2: Distribuição do grau de dificuldade dos agricultores rurais para os critérios gerais de implementação do sistema de rastreabilidade da cadeia de horticultura*.

\begin{tabular}{lcc}
\hline \multicolumn{1}{c}{ Critérios } & Menor dificuldade (\%) & Maior dificuldade (\%) \\
\hline Infraestrutura de TI & 62,5 & 17,5 \\
Investimento de Capital & 50,0 & 50,0 \\
Cadastro de fornecedores & 100,0 & 0,0 \\
Documentação de insumos & 100,0 & 0,0 \\
Treinamento do pessoal & 25,0 & 75,0 \\
Identificação dos alimentos & 12,5 & 87,5 \\
Captura do registro & 25,0 & 75,0 \\
\hline
\end{tabular}

*Foi considerando apenas as propriedades rurais que não realizam rastreabilidade. Fonte: Autores.

Um porcento da produção do produtor de grande porte segue as orientaçães da INC 01, com a implementação do sistema de rastreabilidade para atender uma pequena parcela da cadeia varejista de horticultura. De acordo com o produtor o maior grau de dificuldade para implantação do sistema de rastreabilidade está relacionado ao critério de identificação e codificação dos alimentos e o sistema de captura e registro de dados. Além disso, o produtor ressaltou que o grande empecilho para o sistema de rastreabilidade encontra-se "na própria legislação brasileira, visto que não há registro de todos os insumos utilizados na produção agrícola, tais como para a cultura da cebola, salsa, coentro, manjericão e hortelã”. Por outro lado, há insumo que serve para verduras da mesma família, como os insumos de repolho, pode ser utilizado para couve-flor, contudo, não tem o mesmo efeito.

O resultado dessa falta de registro dos diversos produtos utilizados, impacta diretamente no sistema de rastreabilidade da cadeia de horticultura. Em outras palavras, o governo legisla sobre o sistema de rastreabilidade, mas não colabora com o próprio sistema, visto a demora na regulamentação de insumos para a cadeia de horticultura, o que torna contraditória e não contribui para a transparência da cadeia de alimentos. Os produtores acreditam que enquanto o "estado não proporcionar os agrotóxicos permitidos para cada cultura" não haverá a efetiva rastreabilidade.

Considerando que apenas $1 \%$ da produção é rastreada, o produtor de grande porte informou que a implementação do sistema de rastreabilidade não contribuiu para melhoria do processo, ou ainda, não teve ajuste de preço por conta da implementação, tampouco aumentou volume de vendas e agregou em qualidade ou credibilidade; mas entende que o sistema garantiu a manutenção de fornecimento para alguns players do mercado de alimentos. Essa afirmação do agricultor corrobora com o exposto por Silva (2009). Diante desse cenário, o produtor não apontou vantagens do sistema de rastreabilidade, e como desvantagem apontou o alto investimento, aumento do custo de produção, mão de obra direcionada para trabalhar no sistema de rastreabilidade.

Em termos gerais, tantos os produtores de pequeno porte que ainda não implantaram o sistema e o produtor de grande porte, concordam que o sistema de rastreabilidade é interessante, mas que na prática não funciona adequadamente, devido:

1) falta de registro de insumos para a produção agrícola; 
2) forma de comercialização atual com a ocorrência de mesclagem de produtos de diversos produtores, impossibilitando identificar a origem real do produto;

3) falta de suporte do governo quanto a ferramentas de apoio e treinamento dos produtores e distribuidores dos produtos agrícolas;

4) alto investimento do produtor que não é reconhecido no mercado.

\subsection{Implicações do canal de comercialização sobre a rastreabilidade da cadeia de horticultura}

Grande parte da produção dos produtos das pequenas propriedades rurais é vendida para atravessadores da cadeia, que para obterem maior margem de lucro na revenda da produção agrícola, buscam por menor preço e produto agrícolas com maior tamanho e melhor aparência, ainda uma pequena parcela vende direto para feirantes, quitandas e cooperativa. De acordo com o produtor entrevistado sobre o sistema de rastreabilidade, respondeu que: "ideia boa, porém na prática não funciona, há mesclagem dos alimentos nas caixas dos produtos, inviabilizando a rastreabilidade". O produtor de grande porte além de atender atravessadores, atende também grandes players de fastfood, Companhia de Entrepostos e Armazéns Gerais de São Paulo [CEAGESP], entre outros.

Os resultados apresentaram a inexistência de associação entre o nível de escolaridade dos produtores e os critérios de implementação do sistema de rastreabilidade, mas foi observado associação entre esse último e a percepção dos produtores $(p$ $<0,05)$. A maioria dos proprietários entrevistados afirma terem a intenção de implementar o sistema de rastreabilidade e de adequar a INC 01, contudo não preveem aumento do volume de vendas, tampouco melhoria no processo de comercialização, devido a forma atual de venda da produção para atravessadores que repassam aos feirantes. Os produtores ressaltam que o sistema de rastreabilidade é importante quando todos os elos da cadeia estão comprometidos e mantem a integridade dos produtos durante o processo logístico e de distribuição, Figura 3.

Alguns produtores relataram que os atravessadores remanseiam os produtos dos produtores, resultando na mistura de produtos entre diversos produtores de horticultura, o que prejudica o sistema de rastreabilidade, além de prejudicar os produtores que observam as normas de cultivo e o tempo de carência para aplicação de defensivos agrícolas.

Figura 3: Percepção dos produtores sobre a implementação do sistema de rastreabilidade.

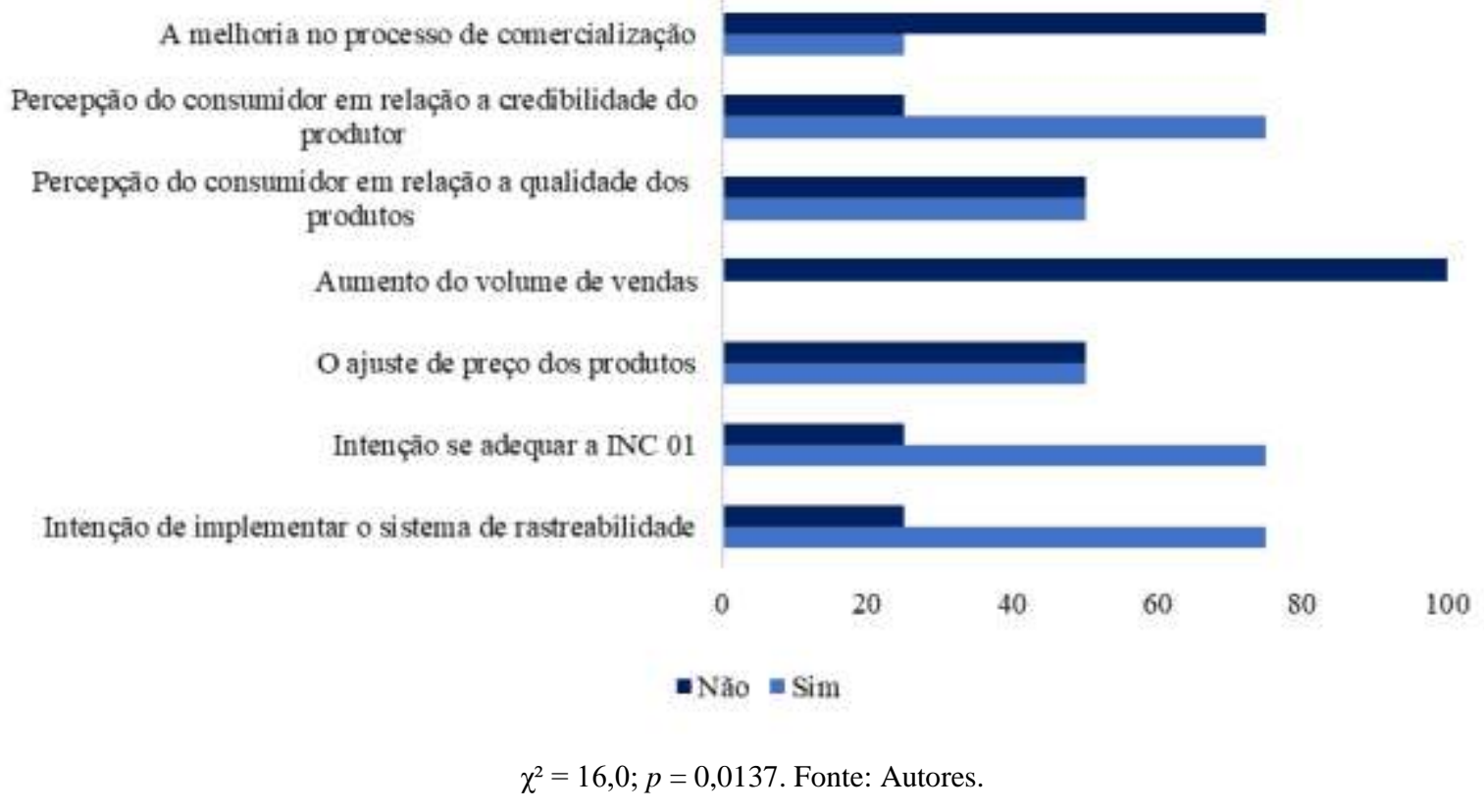


Como já exposto anteriormente, a comercialização de hortícolas ocorre basicamente de duas formas: pé e baciada, prática de mercado; logo, a estruturação do sistema de rastreabilidade requer uma mudança de cultura já enraizada por produtores, comerciantes e consumidores. Além de reforçar o quanto isso dificulta o sistema de rastreabilidade da cadeia.

$\mathrm{Na}$ fase final da entrevista, os produtores foram questionados se a INC pode promover saúde e proteção para população e se a rastreabilidade é algo que deveria ser promovido pela gestão pública. Quanto a primeira questão, a maioria respondeu que sim, pois com a rastreabilidade e a aplicação correta dos defensivos agrícolas não haverá problemas para a saúde da população, contudo, requer maior controle das autoridades visto que na prática, muitos produtores não adotam o tempo de carência e/ou aplicam de forma incorreta gerando preconceitos com relação ao uso de defensivos agrícolas.

Em relação a segunda pergunta, os produtores foram enfáticos em responder que é da responsabilidade do estado, uma vez que as leis estão nas suas mãos, devendo fornecer o suporte seja social, técnico ou financeiro. Um dos produtores participantes respondeu "Sim, a gestão pública deveria ser o primeiro a fornecer insumos e infraestrutura para adequação", outro relatou: "já há dificuldade em relação aos altos valores pagos em insumos para produção, e com a rastreabilidade seria mais um acréscimo que não seria repassado".

Neste contexto foi evidenciado que a rastreabilidade é importante para a cadeia de alimentos, mas considerando as condições atuais em que se encontram os produtores da região do Alto Tietê, verifica-se um descaso por parte do estado e a fragilidade dos produtores que são pressionados a se adequar a um sistema legal que não está totalmente estruturado, faltando orientações, informações e procedimentos importantes para a correta adequação.

\section{Considerações Finais}

A estruturação do sistema de rastreabilidade se inicia com o desenvolvimento da estrutura legal, contemplando todos os insumos utilizados na produção de alimentos. Quando o próprio sistema legal apresenta falhas torna-se inviável a sua implementação e adequação por parte dos produtores. O sistema de rastreabilidade é de interesse de todos e afeta a cadeia produtiva de alimentos, sendo assim, todos os envolvidos são responsáveis pelo manuseio dos produtos que são ofertados ao mercado. O conceito de rastreabilidade ultrapassa o sentido de 'informação sobre a origem', dessa forma, não cabe somente ao produtor garantir as informações e adequações ao sistema, mas também aos atravessadores, empresas de transportes, varejo e distribuidores dos produtos.

Os produtores rurais, principalmente, de pequenas propriedades enfrentam desafios diários para manter sua produção e comercialização dos seus produtores. A dedicação ao campo requer o trabalho diário sete dias por semana, sem direito a folga ou descanso, contando com a ajuda e apoio dos membros da família. Essa ocupação intensiva dos produtores não permite tempo livre para o estudo, treinamento e outras atividades de capacitação. Quando há a necessidade de treinamentos e a participação em atividades extras, os produtores precisam redobrar o trabalho para não prejudicar a produção.

Neste estudo, verificou-se que o grande desafio da implementação do sistema de rastreabilidade encontra-se base legal de registro dos insumos agrícolas, na mudança de cultura e forma de comercialização. Outros desafios como oferecer suporte e apoio aos produtores e distribuidores dos produtos agrícolas, capacitando-os para utilização do sistema.

\section{Agradecimentos}

Os autores agradecem todos os produtores que participaram da pesquisa e contribuíram para os resultados apresentados neste trabalho. 


\section{Referências}

Almeida, A. C., Santos, C. A., Menezes, I. R., Teixeira, L. M., Costa, J. P. R. \& Souza, R. M. (2016). Perfil sanitário de unidades agrícolas familiares produtoras de leite cru e adequação à legislação vigente. Ciencia Animal Brasileira, 17 (3), 303-315.

Anvisa, Agência Nacional de Vigilância Sanitária \& MAPA, Ministério da Agricultura, Pecuária e Abastecimento (2018). Instrução Normativa Conjunta No 2, de 7 de fevereiro de 2018. Diário Oficial [da República Federativa do Brasil], https://www.in.gov.br/materia//asset_publisher/Kujrw0TZC2Mb/content/id/2915263/do1-2018-02-08-instrucao-normativa-conjunta-inc-n-2-de-7-de-fevereiro-de-2018-2915259

Anvisa, Agência Nacional de Vigilância Sanitária. (2019). Programa de Análise de Resíduos de Agrotóxicos em Alimentos (PARA): relatório das amostras analisadas no período de 2017-2018. http://portal.anvisa.gov.br/programa-de-analise-de-registro-de-agrotoxicos-para

Anvisa, Agência Nacional de Vigilância Sanitária \& MAPA, Ministério da Agricultura, Pecuária e Abastecimento (2019). Instrução Normativa Conjunta No 1, de 15 de abril de 2019. Diário Oficial [da República Federativa do Brasil], https://www.in.gov.br/web/dou/-/instru\%C3\%87\%C3\%83o-normativa-conjuntan\%C2\%BA-1-de-15-de-abril-de-2019-86232063

Anvisa, Agência Nacional de Vigilância Sanitária. (2020a). Rastreabilidade de alimentos in natura. http://portal.anvisa.gov.br/documents/33880/4585572/Tema+3.13/36ea570a-e1a4-4126-ae0d-b9618154d516

Anvisa, Agência Nacional de Vigilância Sanitária. (2020b). Agrotóxicos em alimentos. http://portal.anvisa.gov.br/duvidas-sobre-agrotoxicos-em-alimentos

Aung, M. M. \& Chang, Y. S. (2014). Traceability in a food supply chain: Safety and quality perspectives. Food Control, 39 (1), $172-184$.

Brasil. Lei $\mathrm{n}^{\circ}$ 8.629, de 25 de fevereiro de 1993. (1993). Dispõe sobre a regulamentação dos dispositivos constitucionais relativos à reforma agrária, previstos no Capítulo III, Título VII, da Constituição Federal. http://www.planalto.gov.br/ccivil_03/leis/18629.htm

Carvalho, F. A. (2013). Inclusão digital: A influência do ensino de informática como contribuição à gestão rural (Trabalho de conclusão de curso). Fundação Universidade Federal de Rondônia - UNIR, Cacoal, Rondônia, Brasil.

Fávero, L. P., \& Belfiore, P. (2021). Manual de análise de dados. LTC.

Ferreira, V. B., Silva, T. T. C., Garcia, S. R. M. C. \& Srur, A. U. O. S. (218). Estimativa de ingestão de agrotóxicos organofosforados pelo consumo de frutas e hortaliças. Cadernos Saúde Coletiva, 26 (2), 216-221.

Fonseca, W. L., Fonseca, W. J. L., Oliveira, A. A., Vogado, G. M. S., Sousa, G. G. T., Sousa, T. O., Sousa Júnior, S. C. \& Luz, C. S. M. (2015). Causas e consequências do êxodo rural no nordeste brasileiro. Nucleus, 12 (1), 233-240.

Gregolis, T. B. L., Pinto, W. De J. \& Peres, F. (2012). Percepção de riscos do uso de agrotóxicos por trabalhadores da agricultura familiar do município de Rio Branco, AC. Revista Brasileira de Saúde Ocupacional, 37 (125), 99-113.

Hoffmann, R. \& Kageyama, A. (2000). Determinantes da renda e condições de vida das famílias agrícolas no Brasil. Economia, ANPEC, 1 (2), $147-183$.

Ibge, Instituto Brasileiro de Geografia e Estatística. (2017). Censo Agropecuário Mogi das Cruzes. https://cidades.ibge.gov.br/brasil/sp/mogi-dascruzes/panorama

Ibge, Instituto Brasileiro de Geografia e Estatística. (2018). Censo Agro 2017 - Infográfico Produção. https://censos.ibge.gov.br/agro/2017/resultados-censoagro-2017.html

Ibge, Instituto Brasileiro de Geografia e Estatistica. (2019). Censo Agro 2017: população ocupada nos estabelecimentos agropecuários cai 8,8\%. https://agenciadenoticias.ibge.gov.br/agencia-sala-de-imprensa/2013-agencia-de-noticias/releases/25789-censo-agro-2017-populacao-ocupada-nosestabelecimentos-agropecuarios-cai-8-8

Incra, Instituto Nacional de Colonização e Reforma Agrária. Classificação dos imóveis rurais. 2020. https://antigo.incra.gov.br/pt/obtencao-deterras.html?id=234.

Infraestrutura e Meio Ambiente. (2014). O Cinturão Verde. https://www.infraestruturameioambiente.sp.gov.br/institutoflorestal/o-instituto/rbcv/o-cinturaoverde

Loper Aires, C. H. \& Salamoni, G. (2012). Agricultura familiar e as relações sociais de trabalho:um estudo sobre a pluriatividade na Vila Freire - Cerrito RS. Geografia Ensino \& Pesquisa, 17 (1), 41-54.

Marino, L. H. F. C. (2006). Gestão da qualidade e gestão do conhecimento: Fatores-chave para produtividade e competitividade empresarial. XIII Simpep,Bauru, São Paulo, Brasil, p. 1-9.

Paes, R. S. \& Zappes, C. A. (2016). Agricultura familiar no norte do estado do Rio De Janeiro: identificação de manejo tradicional. Sociedade \& Natureza, 28 (3), 385-395.

Pereira, L. T. K., Godoy, D. M. A. \& Terçariol, D. (2009). Estudo de caso como procedimento de pesquisa científica: Reflexão a partir da clínica Fonoaudiológica. Psicologia: Reflexão e Crítica, 22 (3), 422-429.

Porto, L. F. A., Lopes, M. A. \& Zambalde, A. L. (2007). Desenvolvimento de um sistema de rastreabilidade aplicado à cadeia de produção do vinho. Ciência e Agrotecnologia, 31 (5), 1310-1319.

Regattieri, A., Gamberi, M. \& Manzini, R. (2007). Traceability of food products: General framework and experimental evidence. Journal of Food Engineering, 81 (2), 347-356. 
Research, Society and Development, v. 11, n. 1, e7311124446, 2022

(CC BY 4.0) | ISSN 2525-3409 | DOI: http://dx.doi.org/10.33448/rsd-v11i1.24446

Savian, M. (2014). Sucessão geracional: garantindo-se renda continuaremos a ter agricultura familiar? Revista Espaço Acadêmico, 14, 159, 97-106.

Silva, G. J. (2009). Metodologia para inovação tecnológica através de sistema colaborativo de inclusão digital e certificação na agricultura familiar (Tese). Universidade Estadual Paulista, Faculdade de Ciências Agronômicas de Botucatu - UNESP, Botucatu, São Paulo, Brasil.

Silva, E. A. S., \& Machado, S. T. M. (2019). O panorama da mecanização agrícola no Brasil e o atraso da agricultura familiar. $5^{\circ}$ Congresso Internacional de Logística e Operações do IFSP, Suzano, Logística e a Indústria 4.0, Suzano, SP, 1689-1699.

Wiese, A. F., Millanés, O. A. G., \& Bovo, M. C. (2020). As cooperativas de agricultura familiar e o desenvolvimento local: um estudo em dois municípios do Paraná. Revista Perspectivas Contemporâneas, 15 (3), 153-176. 